"Home brew" compared with commercial preparation for enteral feeding

SIR,-We disagree with the comments on the "home brew" preparations for enteral feeding (16 January, p 163).

At Bedford General Hospital we use "home brews" for enteral feeding via either a Ryles or fine-bore tube. Isocaloric feeds are made daily in the ward and administered by trained staff according to instructions given by dietitians; thus there is less contamination and rarely any resultant diarrhoea. Dietitians frequently monitor the feeds and are able to vary them according to the patient's nutritional state.

Mabel Blades

K M PLATT

G ELDER

C CASEY

Bedford General Hospital (South Wing)
Bedford MK42 9DJ

\section{Jogger's blockade}

SIR,-In your recent leading article by Professor Alasdair Breckenridge (20 February, p 532) no mention was made of the fact that beta-blockade exaggerates the increase in plasma potassium which occurs during exercise. ${ }^{12}$

In our study the arterial potassium of a subject undergoing beta-blockade with propranolol $(160 \mathrm{mg} /$ day) rose from $4.0 \mathrm{mmol}$ $(\mathrm{mEq}) / 1$ to $7.8 \mathrm{mmol} / 1$ after 4.5 minutes of exercise on a bicycle ergometer $(100 \mathrm{~W})$. At this point, perhaps fortunately, he was unable to pedal any more. Whether this hyperkalaemia is due to increased release of potassium from exercising muscle, reduced uptake elsewhere, or both is not known; but it may well play an important part in impairing exercise performance.

The potentially harmful effects on the heart of such changes also need to be investigated.

M LIM

R A F Linton

Department of Anaesthetics

D M BAND

Department of Physiology,

St Thomas' Hospital

London SE

${ }^{1}$ Carlsson E, Fellenius E, Lundborg P, Svensson L. Lancet 1978 ;ii:424-5. Lim M, Linton RAF, Wolff CB, Band DM. Lancet
$1981 ; \mathrm{ii}: 591$.

\section{Stopping the haemorrhage from peptic ulcers}

SIR,-Mr A E Young in his leading article on stopping haemorrhage from peptic ulcers (20 February, p 530) referred to our controlled trial ${ }^{1}$ reporting a reduction in rebleeding rate and mortality rate in patients treated by laser photocoagulation. He says that "the statistical validity of this claim has been challenged,"'2 without referring to our rebuttal of this challenge in the following edition of the Lancet $^{3}$ Among other things, we pointed out an error of fact in the letter of Henry and Langman, ${ }^{2}$ who had worked out their statistics on mortality rate on the wrong set of figures, a fact that Professor M J S Langman has since confirmed (personal communication). The statistical validity of the significantly lower mortality rate in the laser-treated group is beyond challenge if the correct figures are used, and it seems a pity that the value of this method of therapy should be dismissed largely on the basis of a calculation error. We therefore wish to set the record straight by referring to our earlier detailed rebuttal. ${ }^{3}$

TIM NORTHFIELD

C P SWAIN

J S KIRKHAM

Norman Tanner Gastroenterology Unit,

St James' Hospital,
London SW12 8HW

S G Bown

Department of Gastroenterology,

University College Hospital,

Swain CP, Bown SG, Storey DW, Kirkham JS, Northfield TC, Salmon PR. Lancet 1981;ii:1313-6, ${ }^{2}$ Henry DA, Langman MJS. Lancet 1982;i i 9 J, Swain CP, et al. Lancet $1982 ; \mathrm{i}: 172$.

SIR,-Mr A E Young's leading article presents a succinct account of a common emergency, that of arresting haemorrhage from a peptic ulcer (20 February, p 530). In conclusion he advisedly states that management includes the efficient replacement of blood loss but he surprisingly omits to mention the muchfavoured use of adequate sedation in the care of the bleeding patient.

Many of us have been trained to prescribe calculated doses of diamorphine in the acute situation with favourable effect in maintaining a stable patient. This treatment as an adjunct to massive transfusion and the administration of alkali is a satisfactory regimen in the actively bleeding ulcer; perhaps we observe success only in those four-fifths of ulcers which are credited with the facility of spontaneously stopping bleeding ?

Graham TANSLEy Layer

Department of Surgery

Department of Surgery,

Canterbury CT1 3NG

Changing attitudes in the management specialist nursing

SIR,-I sincerely hope that the nursing administrators of the Department of Health and Social Security read and absorb the article on the need for specialist nurses in urinary incontinence (27 February, p 645).

Only last week the lecture hall in the Bath postgraduate medical centre was filled with people discussing the care of the aged; and one of the criteria for admissions of individuals to long-stay hospitals and for residential care related to urinary and faecal incontinence. But how many of the community nursing staff have any idea (other than the use of some cumbersome type of pants and pads) of how to deal with this aspect of these patients ?

Some years ago, the DHSS professed concern on this matter; but no form of financial support was offered, and research grants to undertake domiciliary care of these patients with incontinence was refused. Funds from medical research grants had to be found to pursue this activity (in Mr Feneley's case it was the Medical Research Council), and still the DHSS remains dormant.
Attempts at encouraging the hierarchy of the Royal College of Nurses and senior nursing officers in the DHSS to recognise the need to train nurses to be experts in this field (as are others in stoma care, intensive care, etc) fall on deaf and stubborn ears. Presumably this is yet another manifestation of the disorder of having too many clip-board carrying, nonnursing nurses organising the service which they are no longer close to, since they have distanced themselves from the patients by having desks, offices, secretaries, and telephones as their main companions.

It is sad that specialist surgeons (and we still work with patients) feel obliged to cajole other nursing colleagues through medical journals, but if divisional nursing officers and the more centrally placed individuals cannot understand our pleas, how on earth do we get those patients a better deal ?

C A C Charlton

Royal United Hospital,

Bath BA1 3NG

\section{Recurrent cancer after restorative} resection of the rectum

SIR,-There is certainly no more important aspect of rectal cancer surgery than the incidence of local recurrence: this almost invariably leads to the death of the patient and reflects the worst variety of treatment failure. Mr John Maxwell Anderson's leading article (20 February, p 531), however, advocates the simultaneous introduction of all available treatments - that is, surgery, radiotherapy, and cytotoxic drugs-in the manner that is now frequently adopted in the United States. While regarding $\mathrm{Mr}$ Anderson's work most highly and quoting it frequently, we would like to take issue with this "broadside" approach.

Firstly, we cannot accept entirely the assertion that "most reports of recurrences underestimate the true incidence." With modern techniques the staple or suture line is within easy reach of the examining finger, and both pelvic wall and staple line recurrences can be felt, or seen and often biopsied.

Secondly, there is only slender evidence that either radiotherapy or cytotoxic drugs reduce local recurrence, despite extensive trials (of radiotherapy particularly) on both sides of the Atlantic.

Thirdly, the tenfold variation of local recurrence figures from different centres suggests that differences of surgical technique may themselves be important. To quote $\mathbf{M r}$ Anderson in the Scottish Medical fournal, "The five-year incidence of local recurrence is $12-20 \%$ in special interest centres and about $40 \%$ in the country as a whole."1

We have preferred to concentrate on surgical technique directed towards the widest clearance of rectum and mesorectum that is consistent with conservation of the anal sphincters and pelvic floor. We believe that the perirectal lymphatics in the mesorectum may be important and have been concerned by the fact that orthodox anterior resection leaves much of this tissue within the pelvis. Could this explain why anterior resection is the only operative procedure in colorectal surgery which is followed by a significant suture-line or local recurrence rate? Results in our own series will be presented at the Association of Surgeons on 1 April. In essence these report 50 survivors of radical low anterior resection which has been combined with wide excision of the mesorectum, who have been followed for over two years, 
and no case has yet manifested pelvic wall or suture-line disease. None of these cases has received either cytotoxic or radiotherapeutic adjuvant therapy.

Our figures suggest that all but a minority of rectal cancers may be controlled locally by refinement of surgical technique. If this is so we might most profitably direct the adjuvant treatments towards the abortion of hepatic micrometastases in the manner which has been advocated by Taylor and others. ${ }^{2}$

It is surely desirable that we should approach this slow-growing and often localised disease in a stepwise manner and evaluate each modality in turn. In particular trials of adjuvant therapy are unlikely to bear fruit until the surgical technique has been standardised so that we may compare like with like.

R J HEALD ROGER RYALL

Basingstoke Bowel Cancer Clinic, Basingstoke District Hospital,

1 Anderson JM. Scot Med f 1981;26:21-3. 2 Taylor I. Ann R Coll Surg Engl 1981;63:270-6.

\section{Children's accidents}

SIR,-I write to correct the impression about the origin of the BBC programme Play It Safe which might be suggested by Dr K S Cliff's leading article on children's accidents (23 January, p 220). All who had some connection with the programme were delighted with the signal success that accompanied the efforts of the Child Accident Prevention Committee. The initiative, however, lay with a very wellknown educationalist in the West of England, $\mathrm{Mr}$ Leslie Wolff. It was he, as a member of the Education Committee of the Medical Commission on Accident Prevention, who suggested that a series on safety, along the lines of the literacy programme On the Move, should be televised on Sunday evenings in the "slot" between the serial and Songs of Praise. He made the first informal approaches to the BBC in Bristol, as a result of which the commission took the matter up formally with the BBC in London. Leslie Wolff died in December 1980 before seeing the results of his initiative.

Leslie Wolff's ideas were subtly different from the ultimate production. He felt that there was a special need to look at the health of adolescents and to encourage adolescents to fulfil themselves. Safety education he saw as part of this wider aim. This is a more difficult concept than the direct approach of Play It Safe. While the success of Play It Safe was most impressive, it is to be hoped that the $\mathrm{BBC}$ will look again at the original ideas.

Huw Francis Chairman, education committee Medical Commission on Accident Prevention,
London WCix 0JB

\section{Do patients cash prescriptions?}

SIR, - I was interested to read the article by $\mathrm{Mr}$ Aly Rashid (2 January, p 24) entitled "Do patients cash prescriptions ?" I note that his findings-namely, that up to $20 \%$ of prescriptions are not used-have already been the subject of comment in other sections of the press and may well be used as ammunition by various interested parties. In view of the discrepancy between Mr Rashid's findings and those of Cartwright and Dunnell ${ }^{1}$ I thought that it might be worth adding a further contribution to the debate.

In February 1979 I conducted a survey of this "primary" compliance within my practice in Kirkby and Fazakerley, an area in the north part of Liverpool. The method used was quite simple. I kept a carbon copy of all prescriptions issued during the month, which was also the month in which the practice prescribing was being analysed by the Prescription Pricing Authority. At my request the originals were returned to me after the PPA analysis. Out of a total of 681 prescriptions I identified 18 which were not taken to the chemist. This represents a primary non-compliance rate of $2 \cdot 6^{\circ} \mathrm{o}$, which accords with the findings of Cartwright and Dunnell.

The patients in my practice fall predominantly into social classes III, IV, and V, the highest proportion being in class IV. This is the group which Mr Rashid found to have the highest non-compliance rate of all. The study was single blind in that the patients were unaware they were being monitored. This seems to eliminate Mr Rashid's suggestion that Cartwright and Dunnell's compliance rates were influenced by the diary keeping method of monitoring which was used. Another possible variable-namely, my prescribing rate-was no different in the study month from previous and subsequent months. There was no evidence that any particular group of drugs was over-represented in the prescription which were not cashed.

It may be that there are indeed dramatic variations in compliance rates. Perhaps, as in all doctor-patient interactions, the doctor's approach is an important factor? It is clear that further studies will be needed before any sweeping conclusions can be reached.

\section{J A C WINTER}

Liverpool L1 9EH

\section{Acknowledgments to departments of pathology}

SIR,-Minerva has wisely drawn attention (27 February, p 670) to the discourtesy of clinicians who fail to acknowledge the contribution of pathologists and their departments when publishing papers dependent on laboratory results. Sometimes these results are even misquoted or misinterpreted. Most pathologists are scrupulous in including clinicians as coauthors, or acknowledging their assistance, when publishing papers dependent on clinical information.

It is a pity that Minerva does not mention the extra laboratory work often caused by drug trials, or other clinical research projects, and the frequent neglect by clinicians to discuss these in advance with the pathologist. The consequences are, firstly, that the investigations done may not be those that are most relevant to the problem and, secondly, the cost of the investigations comes from the laboratory's fixed budget (and many reagents are very expensive) so that other patients are subsidising the project. All too often such trials are detected when the project is well under way by the laboratory staff noticing, for example, an increase in plasma thyroxine assays coming from one ward. On being challenged the clinician said that he "forgot" the recommended procedure: all such extra work must be discussed in advance, and any necessary payment agreed; if the project involves a drug trial, then the pathologist should be present at a discussion with the clinician and a company representative. Perhaps the representative should initiate the discussion (Association of the British Pharmaceutical Industry please note), or the hospital ethics committee seek the approval of the pathologist when such investigations are planned. Ethics applies between consultants as well as between consultant and patient.

\section{N BARON}

\section{Department of Chemical Pathology,}

Royal Free Hospital and

School of Medicine
London NW3 $2 \mathrm{QG}$

\section{Tailoring hospital facilities to needs}

SIR,-Drs M Atkinson and P J Toghill (30 January, p 344) draw attention once more to the potential contribution of general-practitioner hospitals and small units to lightening the load of district general hospitals. The haphazard development of these hospitals as a largely rural or middle-class phenomenon has meant that the larger industrial conurbations are relatively poorly provided with them. In contrast, many London suburbs, market towns, and retirement areas have an adequate supply of general-practitioner beds.

The findings of Kyle ${ }^{1}$ and Loudon $^{23}$ suggest that the GP hospital can provide care for up to $50 \%$ of total hospital admissions. Nothing could be more valuable in assessing relative hospital needs than a properly funded, up-to-date study, in the manner of Loudon, to indicate where and on what scale new general practitioner beds should be provided. It would then be an easy matter for this sort of study to be reproduced elsewhere to assess local needs.

Rickards's finding ${ }^{4}$ that a 35 -bed unit is the most cost effective is relevant to any new planning. Experience from existing GP hospitals suggests that it would be unwise to attempt to impose a standardised solution for the country as a whole. This particular piece of tailoring cannot be done off the peg, and must be an individual fitting for each community in the best Savile Row fashion.

\section{A J M Cavenagh}

Brecon, Powys

Chairman, Association of General-practitioner Hospitals

\section{Kyle D. Br Med f 1971 ;iv:348-51. \\ Loudon ISL. General Practitioner Hospitals and the Relationship with general practice to hospital medicine. University of Oxford DM thesis, 1973. United Oxford Hospitals, 1971 . \\ Rickards JA. Cost effectiveness analysis of the Oxford community hospital. Oxford: Oxford the Oxford} community hospital. Oxford: Ox
Health Authority (Teaching), 1976.

\section{Consultant numbers}

SIR,-The report of the discussion by the Central Committee for Hospital Medical Services on the Short Report (13 February, p 527) implies that I advocate early retirement as a solution to the problem of numbers. I would like to make it quite clear that I do not support the policy of early retirement for consultants. It is possible to argue that any move to improve career prospects in the socalled "popular" specialties must be examined carefully to avoid continuing encouragement to young doctors to enter these specialties. The existing "market pressures" have not suc- 